\title{
Agata Łuka*
}

\section{Izometrycznie czy z rymem? Nowy przekład zbioru Basia (Pocałunki) lanusa Secundusa}

Jan Everaerts, poeta z Hagi, zwany z łacińska Ianusem Secundusem (1511-1536) pozostawił po sobie $\mathrm{m}$. in. przekłady z greki na łacinę, epigramaty, listy i dzienniki podróży, ale znany jest przede wszystkim jako autor utworów miłosnych: księgi elegii zatytułowanej Iulia (Julia) na cześć jego pierwszej ukochanej oraz słynnego zbioru 19 utworów pt. Basia (Pocałunki) poświęconego drugiej wielkiej miłości poety, którą opiewał pod imieniem Neaera. Basia były chętnie czytane, naśladowane, opracowywane i przekładane tak przez twórców współczesnych Secundusowi, jak i późniejszych. Do dzisiaj doczekały się wielu mniej lub bardziej wiernych oryginałowi przekładów na języki europejskie. Po polsku mamy wolny przekład fragmentów wybranych utworów zbioru Basia pióra Juliana Ejsmonda, zamieszczony w antologii zatytułowanej Podręcznik całowania (Ejsmond 1985: 68-69, 72-74, 79-80, 92, 133-135, 205-207) ${ }^{1}$ oraz ekwimetryczne tłumaczenie całości zbioru dokonane na podstawie przekładu filologicznego Ksawerego Sajewicza przez Wiesława Sienkiewicza (Secundus 1991), posiłkującego się podczas pracy również rosyjskim przekładem S.W. Szerwińskiego. Sienkiewicz pisze we wstępie, że jego przekład jest „pierwszą próbą wprowadzenia twórczości Secundusa w obieg kultury polskiej” (Secundus 1991: 7), ale nie jest to prawdą - przed nim przełożył Basia Arnold Spaet (Secundus 1932), otwierając swą publikacją zbiór Parnassos.

* Katolicki Uniwersytet Lubelski, e-mail: pannonia@kul.lublin.pl

1 Publikacja ukazała się po raz pierwszy w roku 1923, nakładem Towarzystwa Wydawniczego Ignis. Opracowanie zawiera przekład fragmentów Basium 4, 5, 6, 14, 16, 17, 18 i 19. 
W niniejszym artykule prezentuję zarówno spostrzeżenia dotyczące wybranych tłumaczeń, jak i próbkę własnego przekładu Secundusowych „buziaków”2.

Basia to zbiór pełny motywów i zwrotów znanych $\mathrm{z}$ antycznych wierszy o całowaniu, z najbardziej chyba rozpoznawalnym Katullusowym da mi basia mille ${ }^{3}$ - „daj buziów tysiąc”, jak to wieki później przełożył Franciszek Dionizy Kniaźnin4. Herman Sternbach pisze w recenzji przekładu Spaeta: „Czytelnik, obznajomiony z literaturą łacińską, znajdzie niewątpliwie w Basia niejedno z erotycznego inwentarza, znanego mu z przebogatej domeny miłosnej Ovidiusa i triumvirów miłości ${ }^{5}$ [...]. Artyzm zaś leży w tem, że dla jednego i tego samego motywu [poeta] dziewiętnaście znalazł warjacyj, które ani nie nużą, ani nie nudzą” (Sternbach 1932). „Pocałunkowe" wiersze Secundusa to nie tylko księga rachunkowa, ale i podręcznik artis basiandi (usta nieraz radzą sobie same, innym razem przychodzą im w sukurs język i zęby). Jak antycznym, tak i Secundusowym „całowankom”6 nieobcy jest ból, i to nie tylko będący psychiczną udręką wywołaną niespełnieniem w miłości, ale i ból fizyczny. Nie brak tu też pary gołębi, ukazanych jako magistri basiorum, ani opisu konsekwencji pocałunku - zjednoczenia zakochanych poprzez wymianę dusz ${ }^{7}$, chciałoby się powiedzieć, metodą usta-usta, i nie jest to, bynajmniej, tylko wymiana oddechów, o jakiej donosi Bolesław Leśmian słowami: „Tchem się swoim do tchu jej przedostał”, mówiąc o takim, co przemocą dziewczynę „sponiewierał wargami”8 (i nie tylko to). Secundus nie jest jedynym naśladowcą antycznych mistrzów pocałunku, temat ten podejmowali przed nim inni poeci renesansowi, jak Giovanni Pontano w zbiorze Amores czy Kallimach Buonacorsi w swych Carmina (De suavio Fanniae 41; De suavio Fanniae 50; Ad Fanniam 61)․ Chociaż za pierwszego naśladowcę Katulla uznaje się Antonia Boccadellego zwanego Panormitą, to przełomu w lekturze i naśladowaniu poety z Werony dokonał przyjaciel i uczeń Panormity,

2 Przekład zbioru Basia jest częścią książki zawierającej przekład i omówienie dzieł poetyckich Secundusa (Secundus 2018, w przygotowaniu do druku).

3 Carmen 5 (Vivamus, mea Lesbia), w. 7 (Catullus 1980: 4-5).

4 To urocze sformułowanie znajduje się w będącym parafrazą wiersza Katullusa erotyku Kniaźnina (Erotyki VI 10: Z Katulla [1]) o incipicie Żyjmy, ma Różo (Katullus 1956: 144).

5 Triumviri amoris to Katullus, Tibullus i Propercjusz.

6 Słowem „całowanki” przekładał Katullusowe Basia Sęp Szarzyński. Powtarzam to za Grażyną Urban-Godziek (2009: 40).

7 Motyw pocałunku „wyposażony w średniowieczno-petrarkistowską magiczną moc” wykorzystał Secundus również w elegiach (I 3, I 4 i I 5) (Urban-Godziek 2005: 130 i 132).

8 Wiersz pt. Mak, w. 8 (Leśmian 1989: 48).

9 O motywach klasycznych w dotyczących pocałunków wierszach Kallimacha i Pontana wspomina M. Łukaszewicz-Chantry (2014: 102-104). O „pocałunkowych” wierszach Pontana i jego roli jako poetyckiego pośrednika między Katullem a poetami renesansu pisze G. Urban-Godziek (2009: 49-58). 
Giovanni Pontano, będący wraz ze swym odkryciem - kluczem do zrozumienia Katullusa za pomocą jego naśladowcy, Marcjalisa - ogniwem łączącym pomiędzy Katullusem a literaturą renesansową ${ }^{10}$. Basia to kronika gestów i emocji towarzyszących całowaniu, od spojrzeń, uścisków i próśb o pocałunek, poprzez zdawkowe cmoknięcia w usta, przekomarzanie się, niecierpliwość, podniecenie, aż do petite mort, „niedoumierania”, jak tego typu finał spotkania nazwał znawca tematu, a przynajmniej na takiego się kreujący, Bolesław Leśmian (Leśmian 1989) ${ }^{11}$. Słowem, „w tych 19 dyferencjacjach całowania leży cała skala uczuć, rytmów i tonów serca i zmysłów, jakie budzi miłość, przeżywana jako potęga kosmiczna” (Sternbach 1932: 200).

Zza tak barwnego wachlarza doznań, rozpiętego z artyzmem i finezją, Muza spogląda na tłumacza z kuszącym uśmiechem zachęty, niemniej czyha nań również niebezpieczeństwo utraty kolorytu oryginału. Nie śmiałabym oceniać tłumaczy, którzy podjęli próbę przyswojenia polszczyźnie Secundusowego zbioru Basia, chciałabym jednak odnieść się do nich, mimo że sięgnęłam po ich przekłady dopiero po dokonaniu własnego, by uniknąć sugerowania się rozwiązaniami translatorskimi i pomysłami innych. Pominę tutaj parafrazy Juliana Ejsmonda, którego celem nie było zresztą dostarczenie czytelnikowi przekładu wierszy Secundusa, lecz tylko przypomnienie go jako jednego z wielu autorów piszących o całowaniu. Trzeba jednak przyznać, że propozycje Ejsmonda cechuje polot, fantazja i poczucie humoru, znane czytelnikowi z jego przekładu Sztuki kochania Owidiusza (Owidiusz brw). Z kolei przekład Wiesława Sienkiewicza wydaje się chropawy, niedopracowany, roboczy nawet, a miejscami rażą w nim błędy stylistyczne (np. w w. 1 Basium 3: „Dla mnie daruj całusa”), co czyni tłumaczenie trudnym w odbiorze. Tłumacz zachował rytm zastosowanych przez Secundusa miar, a są to: dystych elegijny (Basium 1, 3, 6, 10, 11, 13, 15, 17 i 19), dystych pytyjsko-jambiczny I (Basium 2), jedenastozgłoskowiec falecejski (Basium 4, 5, 12, 14, 18), glikonej i ferekratej (Basium 7), dymetr jambiczny katalektyczny (Basium 8), strofa alcejska (Basium 9), strofa asklepiadejsko-glikonejska II (Basium 16). Odzwierciedlenie metryki oryginału niewątpliwie wymagało wiele trudu, niemniej tłumaczenie zdaje się nużącym i sztucznym właśnie ze względu na ekwimetrię. W polskiej tradycji

10 W zbiorze Hermaphroditus (1425) Panormita raczej nawiązuje do Katullusa, niż go naśladuje; inspiracją tego obscenicznego zbioru epigramatów były głównie Carmina Priapea, utwory Marcjalisa i Plauta. Ale to on rozpowszechnił użycie jedenastozgłoskowca falecejskiego, który dzięki patronatowi Katullusa został uznany za drugie metrum epigramatyczne. Pontano z kolei dał swojej epoce czytanie Werończyka przez pryzmat epigramatów Marcjalisa - „odarte z liryzmu i subtelności właściwej Katullusowi, motywy jego poezji w dużej mierze ukształtowały europejską recepcję pierwszego liryka rzymskiego" (Urban-Godziek 2009: 42-43).

11 Wiersz pt. Nocą umówioną, w. 12 (Leśmian 1989: 108). W podobnym kontekście w w. 7 wiersza pt. Gad pojawia się „rozkosz trwalsza nad zgon” (Leśmian 1989: 39). 
przekładu dominują tłumaczenia rymowane ${ }^{12}$ oraz rytmizowane; ze względu na to, że większość antycznych miar wierszowych brzmi po polsku nienaturalnie czy wręcz wymuszenie, niezwykle rzadko natrafiamy na przekład skomponowany tak, by czytelnik poznał rytm łacińskiego oryginału, przy czym w najlepszej sytuacji jest w liryce strofa saficka przyswojona polszczyźnie przez Jana Kochanowskiego (1530-1584), a w epice heksametr ${ }^{13}$. W moim odczuciu najbardziej wyrafinowany, trafny i pomysłowy jest przekład Arnolda Spaeta, inwencją dorównujący Secundusowi, rymowany (jedynie Basium 6, naśladujące dystych elegijny, jest pozbawione rymów), zazwyczaj z podziałem na strofy, z ciekawymi rozwiązaniami, jak np. w Basium 5, ujętym w cztery strofy czterowersowe, z których każda zakończona jest wezwaniem: „Neero!”. Moje własne propozycje przekładu zbioru Basia to zarówno tłumaczenie ekwimetryczne (jednak!), jak i rymowane, a niekiedy posiadające obie te cechy. Postanowiłam również, co w naszej rodzimej poezji jest zjawiskiem przyjętym, nadać utworom tytuły ${ }^{14}$. Ocenę swych wyborów i decyzji translatorskich pozostawiam Czytelnikowi.

\section{Basium 3}

Da mihi suaviolum, dicebam, blanda puella;

libasti labris mox mea labra tuis.

Inde, velut presso qui territus angue resultat, ora repente meo vellis ab ore procul.

Non hoc suaviolum dare, lux mea, sed dare tantum est desiderium flebile suavioli.

12 Więcej o tradycji rymu w polskim przekładzie antycznych dzieł greckich i łacińskich pisze Ewa Skwara (2012: 150-164).

13 Więcej piszę o tym, omawiając niektóre przekłady Horacego (Łuka 2014: 80-84).

14 Niektóre tytuły są cytatami z literatury polskiej, przywodzącymi na myśl tekst źródłowy, co jest zabiegiem zamierzonym. Dla łatwiejszej identyfikacji utworów pozostawiłam numerację przyjętą w wydaniach zbioru Basia Secundusa. Moja propozycja tytułów wygląda następująco: 1. Geneza pocałunku. 2. Pocałunek poza grób. 3. Usta spłoszone. 4. Pocałunek jej, ach, nektar boski! (zaczerpnięte z Dziadów części IV, w. 314 Adama Mickiewicza, 1994: 52). 5. Całuj, całuj gorąco (z piosenki Violetty Villas Całuj goraco, muz. M. Sewen, sł. A. Jastrzębiec-Kozłowski, 1986). 6. Pocałuj raz, pocałuj dwa (z piosenki Marty Mirskiej pod tym samym tytułem, muz. J. Styne, sł. polskie H. Rostworowski, 1948). 7. Patrzeć czy całować. 8. Pocałunek modliszki. 9. Dług całusowy. 10. Gra w buziaki. 11. Usta prawdy. 12. Niewinne pocałunki. 13. Życiodajny pocałunek. 14. Kto po wzięciu pocałunku i po dalszą część nie sięga... (z przekładu Owidiuszowej Ars amatoria pióra J. Ejsmonda, Sztuka kochania I 15, w. 377378, Owidiusz brw: 23). 15. Warg ogród wonny. 16. Instrukcja całowania. 17. Masz takie usta czerwone... (z piosenki Ewy Demarczyk Groszki i róże, muz. Z. Konieczny, sł. H. Rostworowski i J. Kacper, 1966). 18. Najpiękniejsze usta świata. 19. Usta słodkie jak miód. 


\section{Usta spłoszone}

Powiedziałem: „Daj buziaka, nimfo słodkousta”,

A ty na to bez wahania cmoknęłaś mnie w usta,

Lecz choć takim wykazałaś się temperamentem,

Jakbyś węża nadepnęła, cofasz się ze wstrętem.

I to ma być pocałunek? Nie! To, mówiąc szczerze,

Zaostrzenie apetytu, że aż rozpacz bierze! (A.Ł.)

\section{Basium 10}

Non sunt certa meam moveant quae basia mentem, uda labris udis conseris, uda iuvant;

nec sua basiolis non est quoque gratia siccis,

fluxit ab his tepidus saepe sub ossa vapor.

Dulce quoque est oculis nutantibus oscula ferre, auctoresque sui demeruisse mali:

sive genis totis, totive incumbere collo, seu niveis umeris, seu sinui niveo,

et totas livore genas, collumque notare, candidulosque humeros, candidulumque sinum; seu labris querulis titubantem sugere linguam, et miscere duas iuncta per ora animas, inque peregrinum diffundere corpus utramque, languet in extremo cum moribundus amor.

Me breve, me longum capiet, laxumque, tenaxque, seu mihi das, seu do, lux, tibi basiolum.

Qualia sed sumes, nunquam mihi talia redde: diversis varium ludat uterque modis.

At quem deficiet varianda figura priorem, legem submissis audiat hanc oculis,

ut, quot utrimque prius data sint, tot basia solus dulcia victori det, totidemque modis.

\section{Gra w buziaki}

Właściwie nie wiem, jakie pocałunki są najfajniejsze...

Bardzo lubię na przykład wilgotny dotyk twych warg,

Ale muśnięcia ustami także mają swój urok,

$\mathrm{W}$ takich chwilach gorących rozkoszy przeszywa mnie prąd.

Przyjemnie jest też całować oczy twoje przymknięte,

W ten sposób się przymilając tym sprawcom udręki mej.

Miło jest obsypywać pocałunkami policzki,

Szyję, ramiona śnieżne i śnieżną twoją pierś. 
Śladami ukąszeń miłosnych policzki i szyję naznaczyć, I śnieżnobiałe ramiona, i piersi białe jak śnieg,

Lub ssać wśród westchnień twój język w ustach moich błądzący

I duszę z duszą połączyć, przywarłszy ustami do ust,

I trwając w tym pocałunku, duszami się w końcu zamienić,

Gdy miłość z sił już opada, jakby dotknęła jej śmierć.

Spodoba mi się krótki, długi, nieśmiały, namiętny

Pocałunek - nieważne, czy ja całuję, czy ty.

Tylko nie odpowiadaj całusem mi takim samym,

Niech każdy ruch wygląda inaczej w grze naszych ust.

A komu zabraknie pomysłu na kolejną figurę,

$\mathrm{Z}$ pokorą pokonanego niech słucha reguły tej:

Ile razy cię pocałowano, tyle razy ty teraz

I na tyle samo sposobów całuj zwycięzcę w tej grze. (A.Ł.)

\section{Basium 17}

Qualem purpureo diffundit mane colorem quae rosa nocturnis roribus immaduit; matutina rubent dominae sic oscula nostrae, basiolis, longa nocte, rigata meis:

quae circum facies niveo candore coronat, virginis ut violam cum tenet alba manus.

Tale novum seris cerasum sub floribus ardet, aestatemque, et ver cum simul arbor habet.

Me miserum! quare, cum flagrantissima iungis oscula, de thalamo cogor abire tuo?

$\mathrm{O}$, saltem labris serva hunc, formosa, ruborem, dum tibi me referet noctis opaca quies.

Si tamen interea cuiusquam basia carpent, illa meis fiant pallidiora genis.

\section{Masz takie usta czerwone...}

Barwą, jaką w purpurze poranka róża roztacza,

Gdy nocnej rosy ostatnie kropelki na płatkach jej lśnią,

Czerwienią się o poranku usteczka mojej dziewczyny,

Gdy, pocałunkami je rosząc, nie dałem im spać długo w noc:

Kwitną one przepysznie na śnieżnobiałej twarzyczce, Jak w jasnej dłoni dziewczęcej kwiatuszek fiołkowy są Albo jak świeża wisienka na jeszcze kwitnącej gałązce, Jakbyś patrzył na drzewo i w lata, i w wiosny czas. 
Co za los! Dlaczego zatrzymujesz mnie, całując żarliwie,

A jednocześnie każesz z sypialni odejść twej?

Tę czerwień ust, moja piękna, zachowaj przynajmniej do chwili,

W której mnie tu do ciebie znów przyprowadzi noc,

Lecz jeśli w międzyczasie innego będziesz całować,

Niech usta zbledną ci bardziej niż pobladły z zazdrości ja sam. (A.Ł.)

\section{Bibliografia}

\section{Źródła i przekłady}

Catullus C.V., 1980, Carmina, recogn. brevique andotatione critica instruxit R.A.B. Mynors, Oxonii.

Katullus, 1956, Poezje, przeł. A. Świderkówna, oprac. J. Krókowski, Wrocław-Kraków.

Owidiusz [brw], Sztuka kochania, wolny przekład J. Ejsmonda, Lublin.

Secundus I., 1932, Pocałunki, z łac. oryginału przeł. A. Spaet, wstęp napisał R. Ganszyniec, Lwów.

Secundus I.N., 1991, Pocałunki, przeł. W. Sienkiewicz, Kraków.

Secundus I., 2018, Poezje, przeł. A. Łuka, Lublin (w przygotowaniu do druku).

\section{Słowniki i opracowania}

Ejsmond J., 1985, Podręcznik całowania, Warszawa.

Forcellini (red.), 1940, Lexicon Totius Latinitatis, Ae. Forcellini, t. III, Patavii.

Grimal P., 1987, Słownik mitologii greckiej i rzymskiej, red. nauk. J. Łanowski, hasła przeł. M. Bronarska i in., przedmowę przeł. J. Łanowski, Wrocław.

Łuka A., 2014, Translatorskie losy pieśni Horacego Ad Lydiam meretricem, „Między Oryginałem a Przekładem" 26, Przekład w kulturze, s. 79-100.

Łukaszewicz-Chantry M., 2014, Kobieta jako postać literacka $w$ łacińskiej poezji renesansu. Italia i Polska, Wrocław.

Plezia M. (red.), 1999, Słownik łacińsko-polski, t. IV, Warszawa.

Skwara E., 2012, Kłopotliwi mistrzowie, czyli o rymotwórcach tłumaczących literature antyczna, „Przekładaniec” 26, Kraków, s. 150-164.

Sternbach H., 1932, Joannes Secundus, Pocałunki, przeł. A. Spaet, wstęp napisał R. Ganszyniec (recenzja), „Kwartalnik Klasyczny” 6/2, s. 200.

Urban-Godziek G., 2005, Elegia renesansowa. Przemiany gatunku $w$ Polsce $i w$ Europie, Kraków. 
Urban-Godziek G., 2009, Magistri basiorum - neoplatońskie wariacje na temat katullańskich pocatunków. Od Giovannniego Pontana do Jacobusa Pontanusa, [w:] K. Rzepkowski (red.), Aemulatio \& Imitatio. Powrót pisarzy starożytnych w epoce renesansu, Warszawa, s. 39-58.

\title{
Pozostałe
}

Leśmian B., 1989, Poezje wybrane, wybór i wstęp Cz.M. Szczepaniak, Warszawa. Mickiewicz A., 1994, Dziady, cz. II i IV, Poznań.

Agata Łuka

\section{Choosing between isometry and rhyme. A new Polish translation of lanus Secundus' Basia}

\author{
Summary
}

Jan Everaerts, a poet from The Hague, also known as Ianus Secundus (1511-1536) gave the posterity his translations from Greek into Latin, epigrams, letters and travel diaries among others, but he is mainly known as the author of love poetry: a book of elegies entitled Iulia in honor of his first beloved and the famous collection of 19 poems entitled Basia (The Kisses), written for the other lady of his heart, named Neaera. Basia were willingly read, imitated and translated both by contemporaries of Secundus and poets of the next centuries; there are plenty of translations of Basia into European languages, more or less faithful to the Latin original. In Polish we may read Pocatunki (The Kisses) by Arnold Spaet (1932) and by Wiesław Sienkiewicz (1991) - the latter is an isometric translation based on the philological one by Ksawery Sajewicz. The author of the paper presents both observations on selected Polish translations and a sample of her own translation of Secundus' Basia.

Keywords: lanus Secundus; Basia; Polish translations of Secundus' Basia. 


\section{Izometrycznie czy z rymem? Nowy przekład zbioru Basia (Pocałunki) lanusa Secundusa}

Streszczenie

Jan Everaerts, poeta z Hagi, zwany z łacińska Ianusem Secundusem (1511-1536) pozostawił po sobie m.in. przekłady z greki na łacinę, epigramaty, listy i dzienniki podróży, ale znany jest głównie jako autor utworów miłosnych: księgi elegii zatytułowanej Iulia na cześć jego pierwszej ukochanej oraz słynnego zbioru 19 utworów pt. Basia (Pocałunki) poświęconego drugiej wielkiej miłości poety, którą opiewał pod imieniem Neaera. Basia były chętnie czytane, naśladowane i przekładane tak przez twórców współczesnych Secundusowi, jak i późniejszych. Do dzisiaj doczekały się one wielu mniej lub bardziej wiernych oryginałowi przekładów na języki europejskie. W przekładzie polskim mamy Pocałunki Arnolda Spaeta (1932) oraz Wiesława Sienkiewicza (1991), ten drugi to przekład izometryczny dokonany na podstawie przekładu filologicznego Ksawerego Sajewicza. Autorka artykułu prezentuje zarówno spostrzeżenia dotyczące wybranych polskich tłumaczeń, jak i próbkę własnego przekładu Secundusowych „buziaków”.

Słowa kluczowe: lanus Secundus; Basia; przekłady zbioru Basia na język polski. 